\title{
A extração de diamantes na história geológica e mineral no Paraná
}

\author{
Diamond extraction in mining and geolocical history of Paraná \\ ANTONIO LICCARDO*, LUIZ ANTONIO CHIEREGATI** \\ *Universidade Estadual de Ponta Grossa - aliccardo@uepg.br \\ **Serviço Geológico do Brasil (CPRM) - chieregati@sp.cprm.gov.br
}

\begin{abstract}
Resumo
O início da extração de diamantes no Paraná remonta à segunda metade do século XVIII, poucas décadas depois da descoberta deste mineral em Diamantina (MG). Pouco conhecido em seus aspectos de gênese, depósitos e reservas, este diamante retirado da Bacia do Rio Tibagi e adjacências é estudado há muito tempo e teve vários ciclos de maior ou menor importância econômica. Os depósitos de origem secundária, minerados durante muitos anos por garimpeiros e mergulhadores em pesados escafandros, proporcionam intensos debates quanto à compreensão de sua gênese e alimentam o folclore e a cultura locais. Ao longo da evolução da ciência geológica no Paraná o entendimento sobre estes diamantes recebeu um expressivo aporte de informações, sem que, no entanto, isto resultasse em controles prospectivos ou modelos geológicos mais precisos. Rochas kimberlíticas ou lamproíticas nunca foram localizadas na região, assim como não há indícios de minerais mantélicos que pudessem ser ligados à sua gênese. A associação com as rochas sedimentares glaciogênicas do Grupo Itararé parece ser a melhor possibilidade de fonte, sem maiores comprovações, entretanto. Considerados de importância menor no panorama de produção diamantífera do Brasil, estes depósitos apresentam um contexto histórico especial de cunho científico, socioeconômico e cultural que começa a ser tratado como patrimônio na ótica da valorização da geodiversidade que ocorre em escala mundial. A correlação do conteúdo geocientífico e da história mineral com os aspectos socioculturais é o caminho para que as várias facetas deste contexto ímpar da região de Tibagi sejam devidamente consideradas. Este artigo propõe o aporte da informação geológica para o fortalecimento e valorização do patrimônio imaterial constituído pela memória da extração de diamantes no Paraná.
\end{abstract}

Palavras-chave: diamante; patrimônio mineiro; história da mineração.

\begin{abstract}
The beginning of diamond extraction in Paraná goes back to the second half of 18th century, a few decades after the discovery of this mineral in Diamantina, Minas Gerais. Little known on the aspects of its genesis, deposits and reserves, this diamond from of the Tibagi River basin and vicinity have been studied from long time and had several cycles of greater or lesser economic importance. The secondary source deposits, mined for many years by divers in heavy helmets provide intense debates as to the understanding of its genesis and feed on the folklore and local culture. The efforts to identify huge deposits and/or the primary sources of these diamonds led to a significant amount of geological information about this region, without however, resulting in prospective controls or more accurate geological models. Kimberlitic or lamproitic rocks have never been found in the region, as well as there is no evidence of mantelic minerals that could be linked to its genesis. The connection with the glacio-sedimentary rocks of Itararé Group appears to be the best possible source, however with no further evidence,. Considered to be of minor importance in diamond production of Brazil, these deposits have a historical context of scientific, socio-economic and cultural nature that begins to be treated as equity in the context of global geodiversity discussion. The correlation of scientific content and mineral history with social and cultural aspects is the path for the development of this unique context. This paper proposes the connection between geological data and cultural heritage constituted by the memory of diamond extraction in Paraná.
\end{abstract}

Key words: diamond; mining heritage; mining history.

\section{INTRODUÇÃO}

Entre 1725 e 1866, a maior parte dos diamantes nas cortes europeias era proveniente do Brasil e teve um papel extraordinário na economia e cultura de Portugal. A importância dos diamantes nesta época refletiu-se em toda a Colônia de várias maneiras, inclusive nos desconhecidos depósitos do rio Tibagi, no atual território do Estado do Paraná, segunda ocorrência encontrada até então na América Portuguesa.
Descobertos em 1754, esses sempre foram pouco conhecidos quanto ao seu potencial de produção ou reservas, situação que persiste até hoje. Mesmo sem o controle oficial e produzindo clandestinamente, os depósitos no Paraná participaram da produção brasileira do período áureo (séculos 18 e 19) e sofreram as influências da conjuntura político-econômica. Contudo, algumas diferenças levaram esta região a um contexto socioeconômico menos dependente da mineração, mas sujeita à sua influência por mais de dois séculos.

O aspecto cíclico é uma característica da 
produção no rio Tibagi, com picos de extração em certas épocas que podem ser correlacionados com circunstâncias econômicas e sociais do Brasil, como a migração de garimpeiros baianos no início do século 20 (Liccardo et al., 2012). Condicionantes ligadas à geologia dos depósitos e às características mineralógicas podem ter sido fatores determinantes para este contexto de produção mineral peculiar e fazem destes depósitos um conjunto único em termos científicos e culturais. As Figuras 01 e 02 mostram um típico garimpeiro da região utilizando as mesmas técnicas de prospecção que se utilizava há 200 anos e um mergulhador da década de 1980, ainda utilizando escafandros alimentados por bombeamento manual.

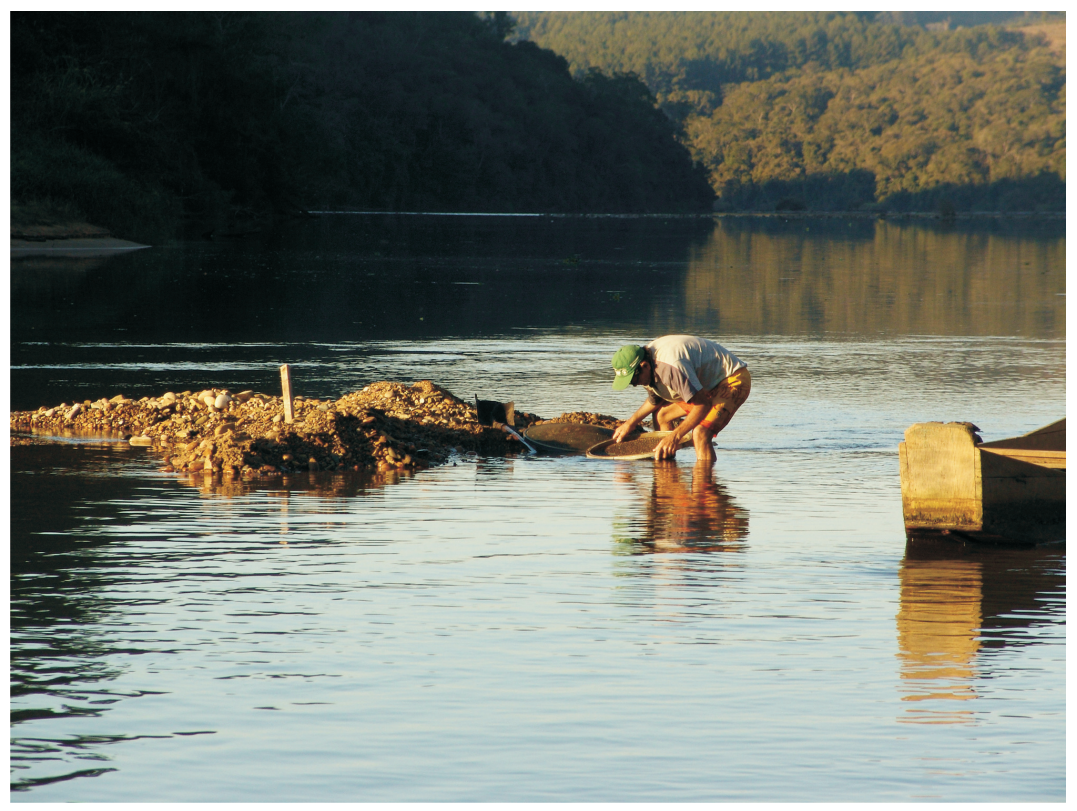

Figura 1 - Aspectos típicos das técnicas de recuperação de diamantes do leito ativo no Rio Tibagi: garimpeiro trabalhando manualmente depósitos de cascalho. Foto A. Liccardo, 2008.

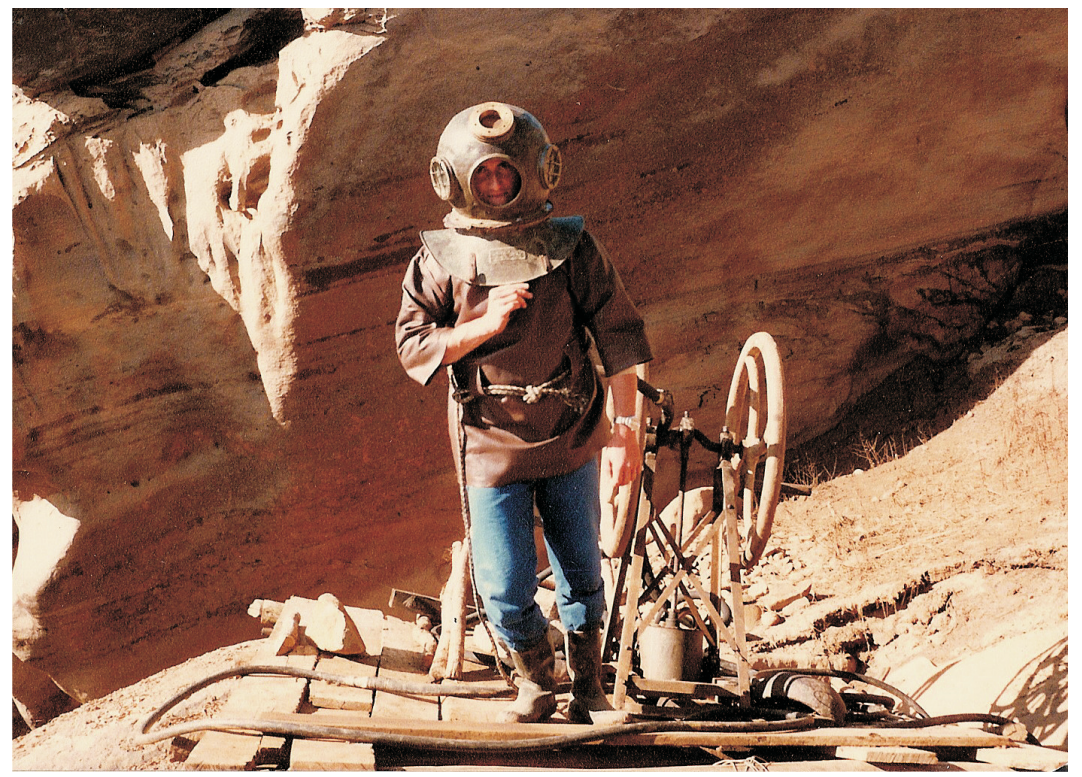

Figura 2 - Aspectos típicos das técnicas de recuperação de diamantes do leito ativo no Rio Tibagi: mergulhador com escafandro para trabalhos mecanizados no fundo do rio. Foto D. Mesquita, 1985. 
Os depósitos encontram-se predominantemente em leito ativo de rios e córregos, com eventuais paleocascalheiras em depósitos de colúvio e elúvio. Com distribuição aparentemente errática, as ocorrências estendem-se por boa parte do
Segundo Planalto Paranaense, com uma forte concentração no rio Tibagi entre a cidade homônima e o município de Telêmaco Borba, não obstante algumas manchas de extração ao norte e ao sul (Figura 03).

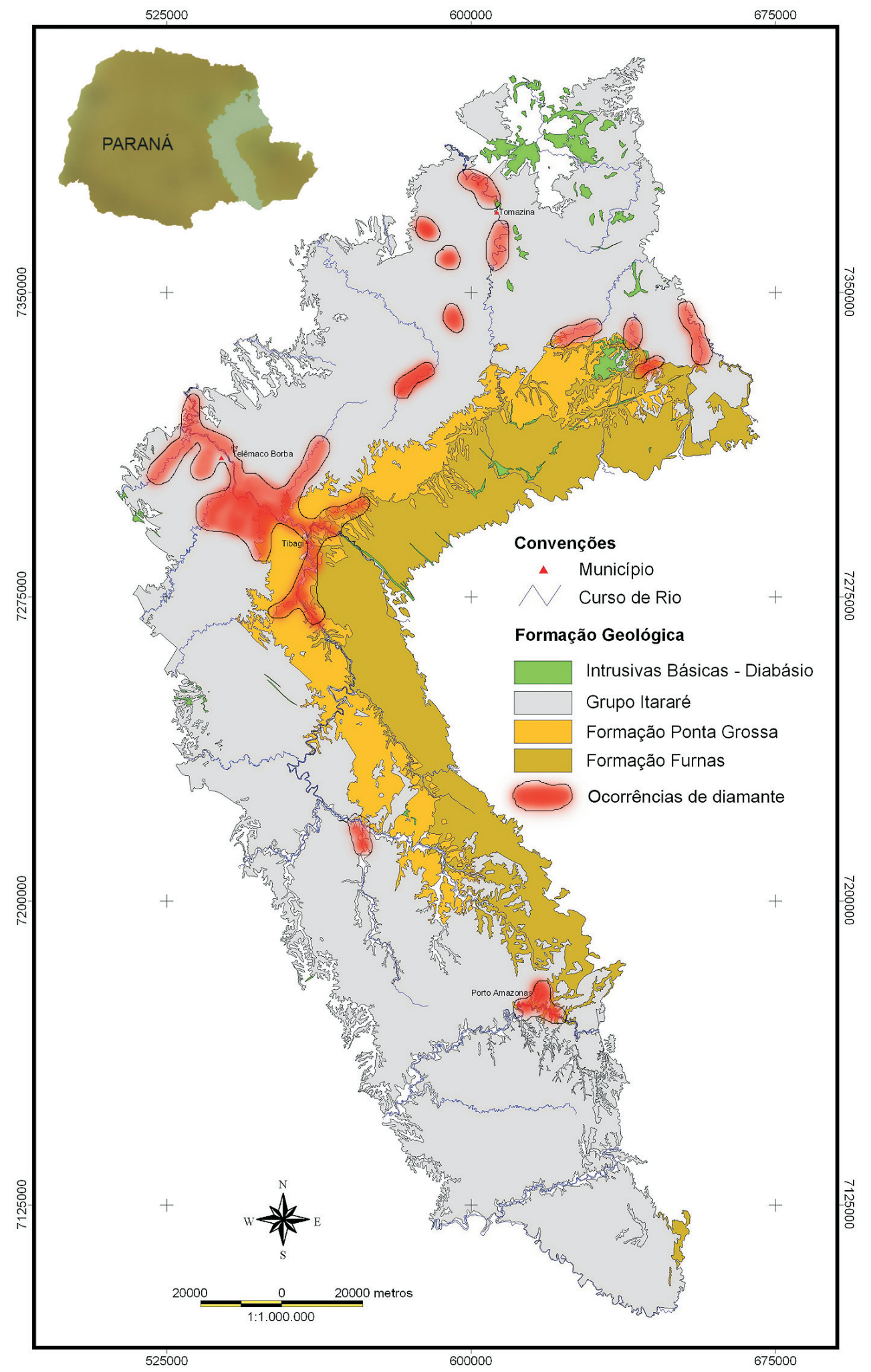

Figura 3 - Mapa de distribuição dos depósitos diamantíferos sobre o Segundo Planalto Paranaense. A mancha entre Tibagi e Telêmaco Borba é a mais significativa, onde a extração se concentrou. Modificado de Mineropar (2006). 
Uma revisão dos dados conhecidos e a possibilidade de correlação com análises socioculturais da região são as propostas deste artigo e podem trazer o aporte da informação geológica ao âmbito da discussão cultural. Este conjunto aponta a atividade de extração de diamantes no Paraná como um tipo de patrimônio imaterial que requer levantamentos mais específicos para a sua eventual preservação.

\section{DA DESCOBERTA AO SÉCULO 19}

O viajante francês Saint-Hilaire (1820), ao passar pelo Paraná, mencionou a existência de contrabandistas de diamante, próximo à Jaguariaíva, e cogitou que este já poderia ser conhecido dos primeiros bandeirantes, no século XVI. O primeiro registro escrito, no entanto, sobre a presença de diamante nesta região é de 1754, por Ângelo Pedroso Lima, quando seu escravo de nome Anselmo, faiscando os córregos em busca de ouro se deparou com uma "pedra cristalina e lustrosa" (sic). Esta foi colocada na coroa de Nossa Senhora da Penha e, posteriormente, entregue ao governador da vila de Santos, Inácio Elói de Madureira (Lopes, 2002).

Em 1802, Martim Francisco de Andrada (irmão de José Bonifácio), então diretor geral das Minas de Prata, Ouro e Ferro da capitania de São Paulo, esteve na região em expedição científica examinando os córregos Monjolo, Faisqueira, Fortaleza, São Domingos, Santa Rosa, Borges e quase todos os braços do Tibagi em ambas as margens. Seu relatório é bastante extenso e detalhado, incluindo uma descrição dos diamantes encontrados. Segundo ele,

\begin{abstract}
"...uns cor de aguardente do reino, outros brancos, cor de prata, e alguns cor de aços cristais brancos $e$ amarelos de ouro...". O mineralogista especula, ainda, sobre as fontes deste mineral: "...os diamantes foram achados em caldeirões tendo sido transportados pelas águas que com as grandes chuvas, rasgando as formações poudinguiças, lavaram-nas e consigo os trouxeram. Quanto porém aos tirados das ditas formações não permanentes, que de riquezas se não deveria esperar quando estas se descobrissem?"
\end{abstract}

Outros famosos viajantes também mencionaram a existência de diamantes neste território, que se estende pelos Campos Gerais do Paraná, a exemplo de Eschwege (1833) que cita o rio Tibagi como sendo o mais rico da região. $O$ engenheiro inglês BiggWither (1878) em sua passagem pelo Paraná apontou o recrutamento forçado de homens para a Guerra do Paraguai (1864-1870) como um fator desestimulante para a mineração na região Sul. Sugeriu, ainda, que a decadência da mineração do diamante só ocorreu por ausência de uma companhia importante, tendo a região sido explorada apenas superficialmente. De fato os garimpos de diamante no Sul nunca dispuseram da grande quantidade de escravos utilizados em Minas Gerais, já que a média de escravos naquela região mais pobre, de economia mais ligada à pecuária, era de um escravo por propriedade menor que 100 ha (Gutierrez, 2006).

Bigg-Wither (1878) citou fatos curiosos em seus diários, que ajudam a dimensionar a produção na época, como a troca de um escravo ao preço de 100 libras por uma xícara de diamantes, ou que o preço usual de um diamante de "pura água" (incolor), pesando um quarto de oitava (1g), era de 50 libras. Relatou, também, o contato com Herbert Mercer sobre uma malograda tentativa de mineração pelos ingleses. Descendentes deste engenheiro publicaram mais tarde importantes relatos sobre os garimpos de Tibagi (Mercer \& Mercer, 1934).

Possivelmente graças à interpretação dos relatos positivistas de Bigg-Wither (1878), disseminou-se a ideia de que por baixo da cidade de Tibagi estende-se um "rico lençol de diamantes", já que o inglês especulou sobre a extensão das paleocascalheiras lavradas a cerca de $5 \mathrm{~km}$ do município. De fato, ainda hoje, nessa localidade conhecida como Lavra dos Ingleses, são produzidos pequenos diamantes.

Ainda em finais de século XIX, intensificou-se o estudo sobre a geologia no Brasil, com os trabalhos de Hartt (1870) que fez referência ao diamante do Tibagi em seus levantamentos e especialmente Derby (1878), que publicou o primeiro estudo detalhado sobre a geologia da província diamantífera do Paraná.

Orville Derby, considerado o pai da geologia paranaense, sugeriu que a possível fonte dos diamantes seriam os arenitos da Formação Furnas (Devoniano) que uma vez trabalhados pelos rios dispersariam estes minerais nos sedimentos do leito.

\section{O CONHECIMENTO E A EXTRAÇÃO A PARTIR DO SÉCULO 20}

\subsection{PRIMEIRA METADE DO SÉCULO}

Por volta de 1912, os garimpos que se encontravam em quase total abandono começaram a receber afluência de garimpeiros vindos de Minas Gerais e Bahia, que se fixaram na região, influenciando a economia e a cultura locais. Com a explosão econômica do diamante entre os anos 20 e 40, outros pesquisadores desenvolveram estudos sobre este mineral e sua geologia. Oliveira (1927), no detalhamento do primeiro mapa geológico do Paraná, escreveu uma nota sobre o diamante, concordando com a origem aventada por Derby (1878), e Bastos (1936) e Oliveira (1937) o relataram mais minuciosamente para o Serviço Geológico Mineralógico.

\footnotetext{
${ }^{1}$ Termo do português arcaico provavelmente proveniente do inglês puddingstone, ou conglomerado.
} 
As informações mais completas, no entanto, são devidas a Oppenheim (1936), do antigo Serviço de Fomento da Produção Mineral, que descreveu os garimpos, enumerou as ocorrências (Tabela 1) e discorreu sobre a geologia e possível gênese deste mineral. Oppenheim (1936) contrapôs-se às ideias sugeridas por Derby e atribuiu a dispersão de diamantes ao desgaste de rochas ácidas do embasamento (pegmatitos), conforme as teorias predominantes em sua época, defendidas principalmente para os diamantes de Minas Gerais por Djalma Guimarães (1933). No entanto o autor apontou como "rocha matriz secundária" no Tibagi sequências glaciais conglomeráticas do Permiano Inferior (atual Grupo Itararé) e descartou qualquer participação das inúmeras intrusões básicas presentes na região. As Figuras 04 a 07 mostram os perfis do rio Tibagi em três pontos distintos, enfatizando as características geomorfológicas dos depósitos diamantíferos, conforme a interpretação de Oppenheim (1936).

\begin{tabular}{|c|c|c|c|c|c|}
\hline 1 & São Francisco & 21 & Pocinho & 41 & Cachoeira Feia \\
\hline 2 & Poço de Carranca & 22 & Limeira & 42 & Salto Aparado \\
\hline 3 & Cachoeira dos Pampas & 23 & Barreirinho & 43 & Poço do Gique \\
\hline 4 & Cachoeira dos Pinheiros & 24 & Caldeirões & 44 & Salto dos Alemães \\
\hline 5 & Mato bom & 25 & Saltinho & 45 & Cachoeirinha \\
\hline 6 & Cachoeira das Cavernas & 26 & Mandasaia & 46 & Chupador \\
\hline 7 & Cachoeira do Bonifácio & 27 & Imbauzinho & 47 & Cachoeira dos Quizamba \\
\hline 8 & Cachoeira da Usina & 28 & Pedra Grossa & 48 & Barra Grande \\
\hline 9 & Cachoeira de Tibagy & 29 & Anta Magra & 49 & Caldeirão \\
\hline 10 & Salto Peludo & 30 & Arroio Grande & 50 & Ilha dos Cavalos \\
\hline 11 & Santa Rosa & 31 & Drummond & 51 & Cachoeira dos Porcos \\
\hline 12 & Cascalho duro & 32 & Cachoeira do Tigre & 52 & Cachoeirinha \\
\hline 13 & Barra da Conceição & 33 & Cachoeirinha & 53 & Cachoeirão \\
\hline 14 & Poço do Assombro & 34 & Vira Panela & 54 & Cachoeira do Horácio \\
\hline 15 & Rio Imbaú & 35 & Estreito & 55 & Poço do Tigre \\
\hline 16 & Saltinho & 36 & Ilha das Formigas & 56 & Cachoeira Grande \\
\hline 17 & Cachoeira dos Ingleses & 37 & Ilha Fechada & 57 & Jaguatirica \\
\hline 18 & Lambedor & 38 & Cachoeira dos Pupos & 58 & Areado \\
\hline 19 & Varanol & 39 & Barra do Lageado & 59 & Salto Mauá \\
\hline 20 & Cachoeira da Mortandade & 40 & Cachoeira Grande & & \\
\hline
\end{tabular}

Tabela 1-Ocorrências de diamante cadastradas por Oppenheim em 1936.

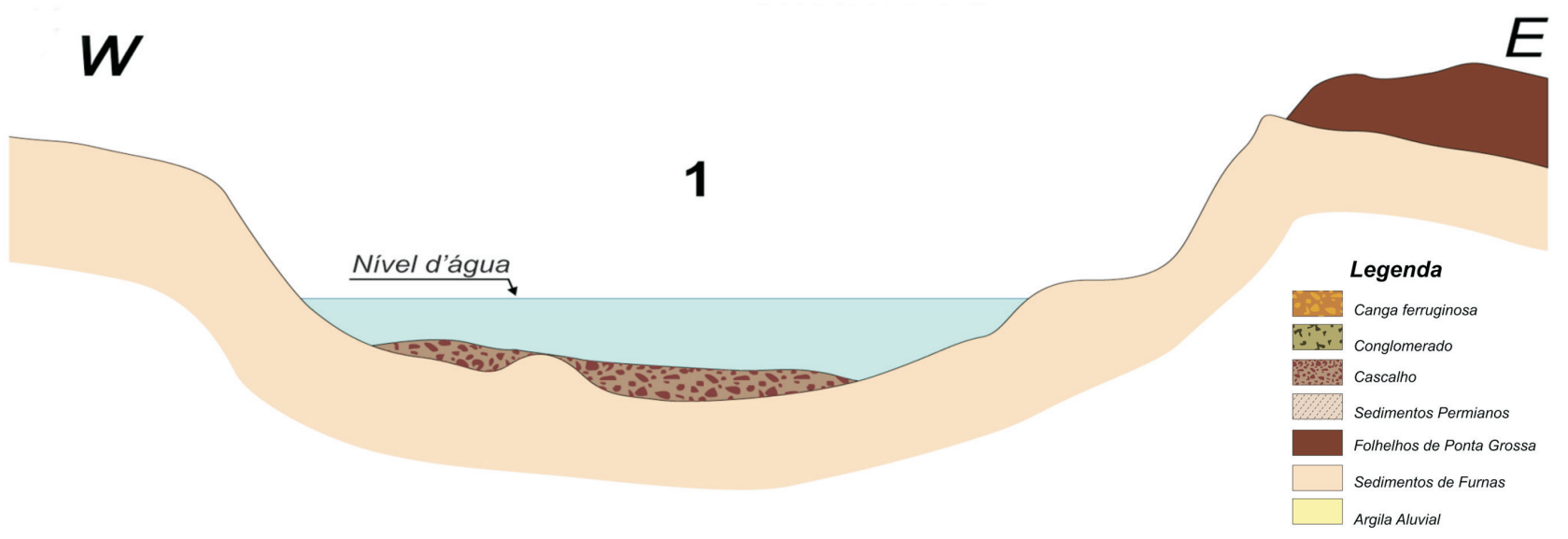

Figura 4 - Perfil transversal do rio Tibagi, num dos garimpos conhecido como Mato Bom acima do município de Tibagi, ilustrando o entendimento, à época, das armadilhas de relevo para os depósitos diamantíferos (baseado em Oppenheim, 1936). 
$N$

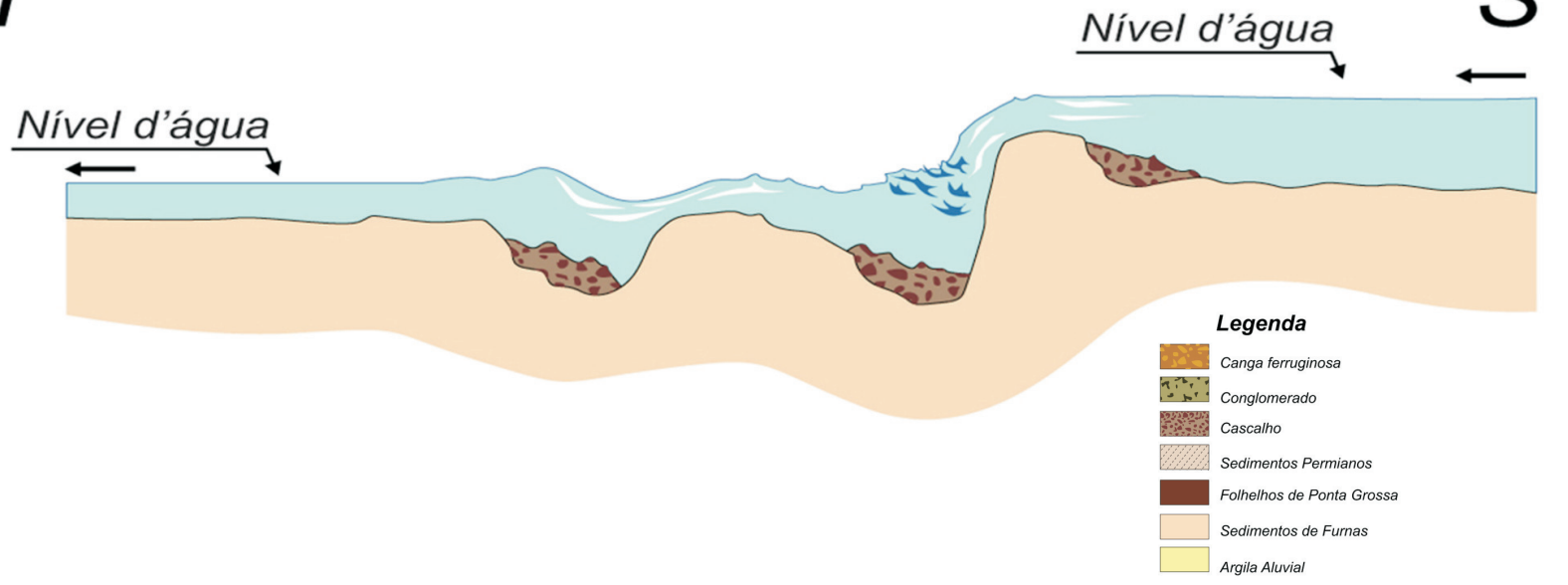

Figura 5 - Perfil longitudinal do rio Tibagi, num dos garimpos conhecido como Mato Bom a montante do município de Tibagi, ilustrando o entendimento, à época, das armadilhas de relevo para os depósitos diamantíferos (baseado em Oppenheim, 1936).

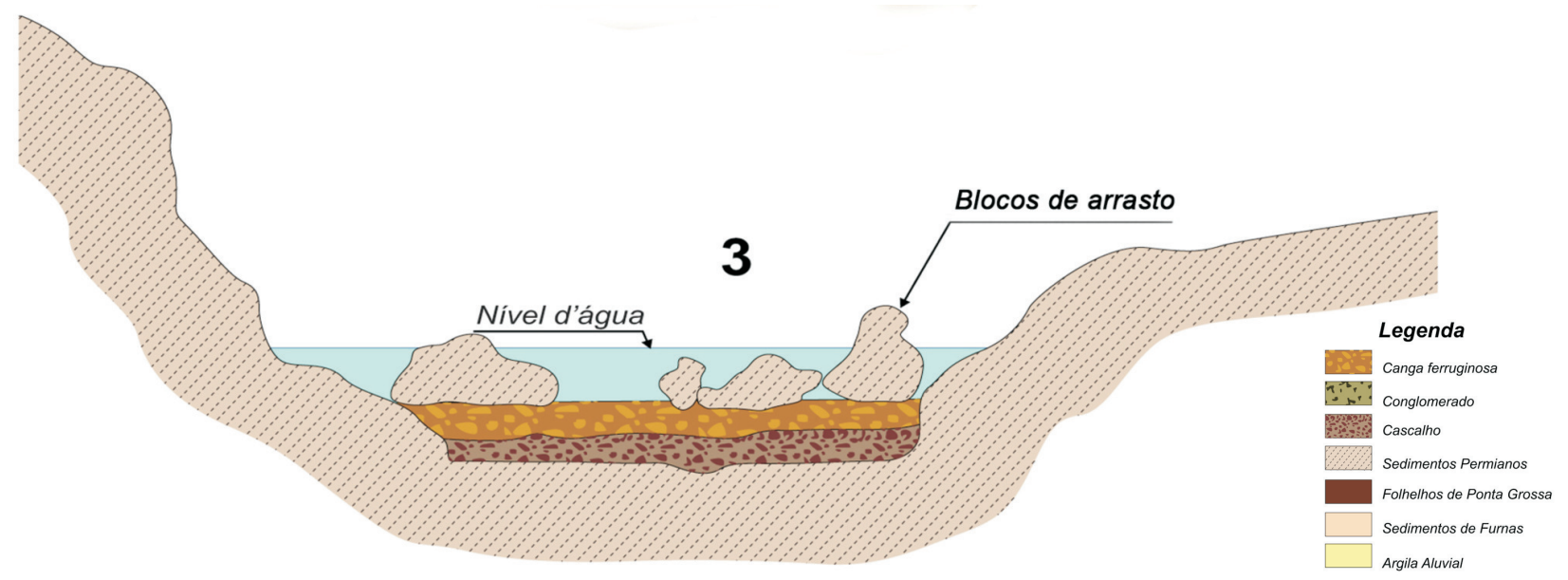

Figura 6 - Perfil transversal mostrando as cascalheiras e sua concentração em certos trechos, nos garimpos de Cascalho Duro, já no município de Telêmaco Borba (baseado em Oppenheim, 1936).

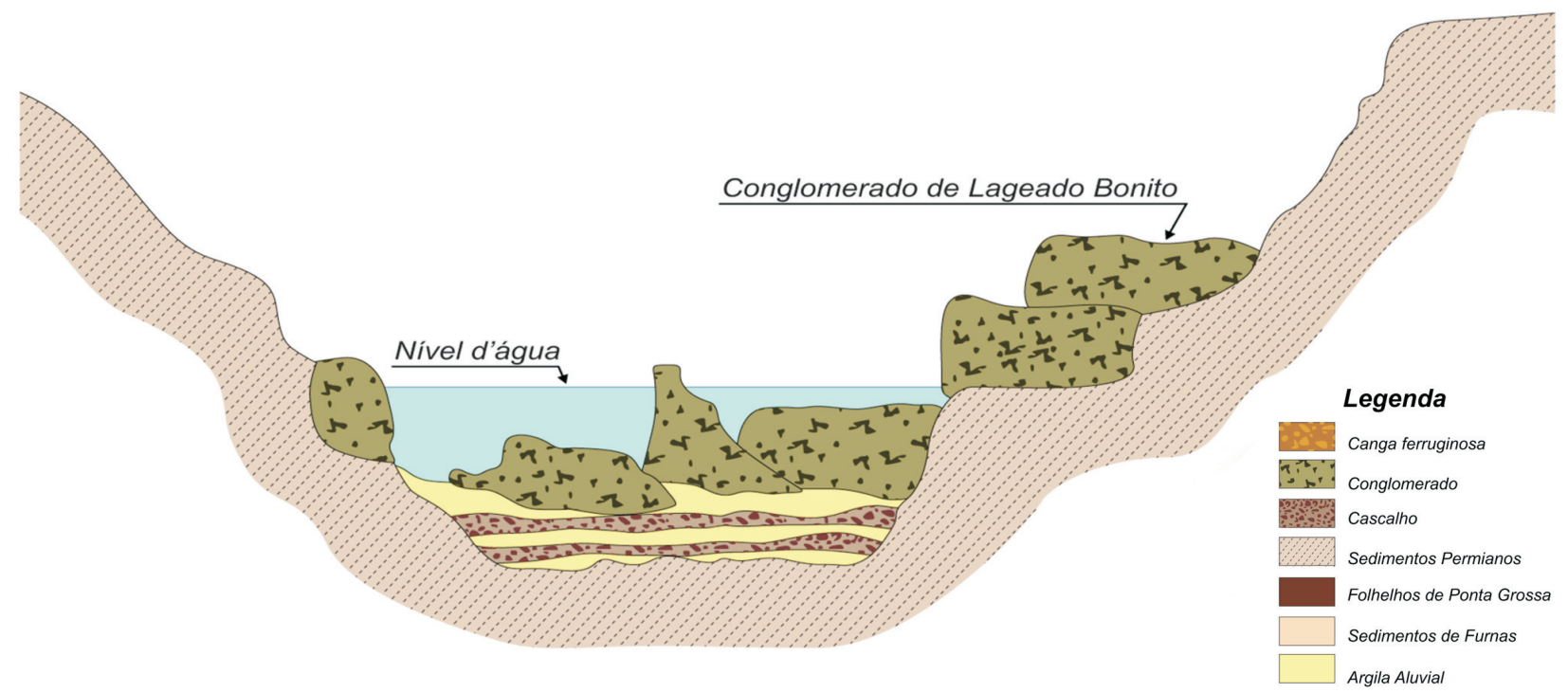

Figura 7 - Perfil transversal mostrando as cascalheiras e sua concentração em certos trechos, nos garimpos de Salto dos Alemães, já no município de Telêmaco Borba (baseado em Oppenheim, 1936). 
Passado este período de intensa garimpagem, Maack (1968) publicou uma comunicação sumária em que afirmou ter extraído diamante das rochas glaciais da região. Este fato, contudo, ainda não foi confirmado por nenhum outro autor e sobre o local exato desta possível extração se perdeu com a morte de Maack.

$\mathrm{Na}$ década de 1980, um novo surto de mineração ocorreu no Tibagi e empresas como a CPRM e a Mineropar implantaram grandes projetos de pesquisa e prospecção na região, incluindo uma lavra experimental (Mineropar) em Campina dos Pupos, no município de Telêmaco Borba. Neste período, Svisero (1979) teve a oportunidade de analisar a mineralogia e as inclusões destes diamantes e Chieregati (1989), em dissertação de mestrado posterior, realizou um extenso panorama sobre a geologia dos depósitos, baseado em numerosos levantamentos de campo da CPRM. Mais tarde alguns dados foram complementados por Perdoncini (1997), também em dissertação de mestrado. Vários trabalhos sobre o diamante de Tibagi foram ainda apresentados em 2010, por ocasião do Simpósio Brasileiro de Geologia do Diamante que aconteceu pela primeira vez em Tibagi, reaquecendo as discussões sobre o tema.

\subsection{LAVRA EXPERIMENTAL DA MINEROPAR}

Entre 1982 e 1987 a Mineropar, à época uma empresa estatal dedicada à pesquisa, prospecção e fomento da mineração, realizou atividades de pesquisa e extração de diamante e ouro na bacia do rio Tibagi em várias localidades, entre elas Ilha dos Cavalos, Barra Grande e Campina dos Pupos, no âmbito do Projeto Diamante. Na localidade conhecida como Campina dos Pupos foi implantada uma lavra experimental que permitiu um detalhamento geológico da morfologia do leito do rio, com seu característico trapeamento. Esta lavra foi realizada em uma parceria da Mineropar com a cooperativa de garimpeiros existente à época, que contava com 55 associados, e com o geólogo detentor dos direitos minerários, Atamon Domingues de Oliveira, sobre um antigo garimpo, caracterizado por cascalheiras que formam ilhas em trechos do rio. As atividades envolveram o desvio das águas por bombeamento contínuo e a construção de uma barragem para secagem do leito, a dragagem para a retirada do cascalho mineralizado transportado por meio de vagonetes e guinchos (ver Figura 08) e a posterior lavagem e separação com uso de jig em local seco, para a recuperação do diamante (Liccardo \& Mesquita, 2010).

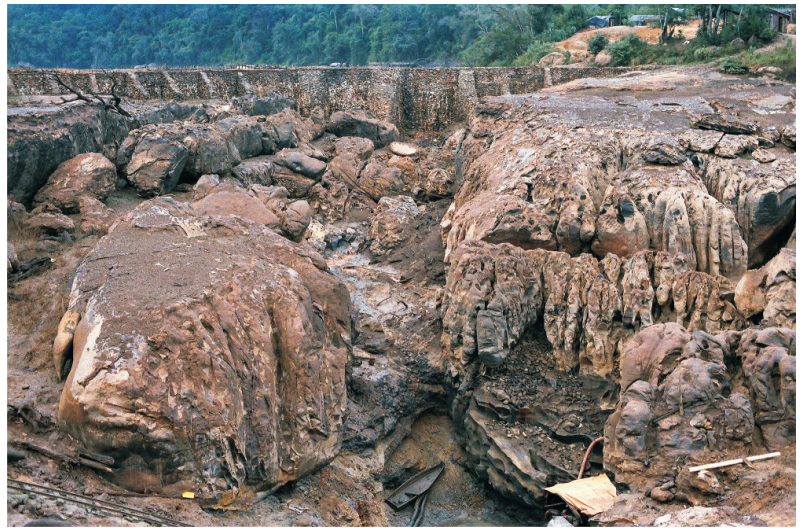

Figura 8 - Imagem da geomorfologia do fundo do rio Tibagi, obtida na época da construção da barragem e desvio das águas. Em alguns trechos a profundidade do rio pode alcançar $30 \mathrm{~m}$ e ficam evidentes as inúmeras armadilhas para concentração de diamante. Atualmente este local, Campina dos Pupos, inclusive o muro, foram cobertos pelas águas, graças à construção da hidrelétrica em Salto Mauá, a jusante. Foto D. Mesquita, 1985.

Registros mantidos desta época indicam a retirada de 6.741 pedras $(1.836,96 \mathrm{ct})$ em três grandes lotes: o primeiro, com 1.628 pedras, pesando $456,11 \mathrm{ct}$, o segundo com 3.206 pedras que totalizavam $848,90 \mathrm{ct}$ (ver Figura 09) e o terceiro lote que se compunha de 1.907 pedras que pesavam $531,96 \mathrm{ct}$. Esses dados permitiram a inferência de algumas características gerais sobre os diamantes produzidos nesta localidade com bastante representatividade, já que os trabalhos eram controlados sistematicamente pelas três partes interessadas e representam, possivelmente, o melhor controle estatístico já realizado em populações de diamantes desta região em mais de 250 anos de extração (considerando a quantidade de espécimes). Das 6.741 pedras $(1836,96$ quilates) retiradas em poucos meses de extração descontínua por problemas com chuvas, percebe-se o tamanho pequeno em média $(0,27 \mathrm{ct})$. Ainda conforme estes registros, o maior destes diamantes pesava 9,10ct (avaliado em US\$ 2.180,00 em novembro de 1985), sendo muito pouco comum nos lotes a presença de pedras com mais de 3ct. O material recuperado nesta lavra experimental foi classificado como tipo gema (41\%), tipo "lasca" (parcialmente aproveitável em lapidação - 19\%) e tipo indústria (40\%). As Figuras 10 a 12 mostram a distribuição dos indivíduos conforme esta classificação e o peso para diferentes lotes (Liccardo \& Mesquita, 2010).

Não obstante as dificuldades para a construção da barragem, que foi interrompida inúmeras vezes em função da grande variação do nível do rio pelas chuvas, e independentemente dos resultados econômicos obtidos, as informações sobre o leito do rio Tibagi nesta época e esta significativa população de diamantes trouxeram novas ideias sobre as características dos depósitos e dos diamantes. 


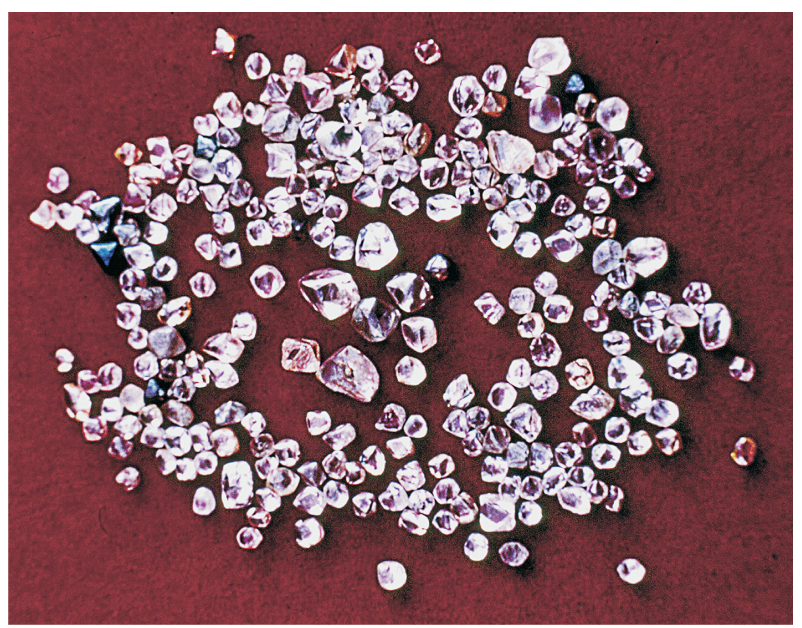

Figura 9 - Parte do segundo lote produzido em 1985 pela lavra experimental na Campina dos Pupos, município de Telêmaco Borba, mostrando as principais características dos diamantes de Tibagi, como a predominância de cristais inteiros por exemplo. Foto: Mineropar, 1985.

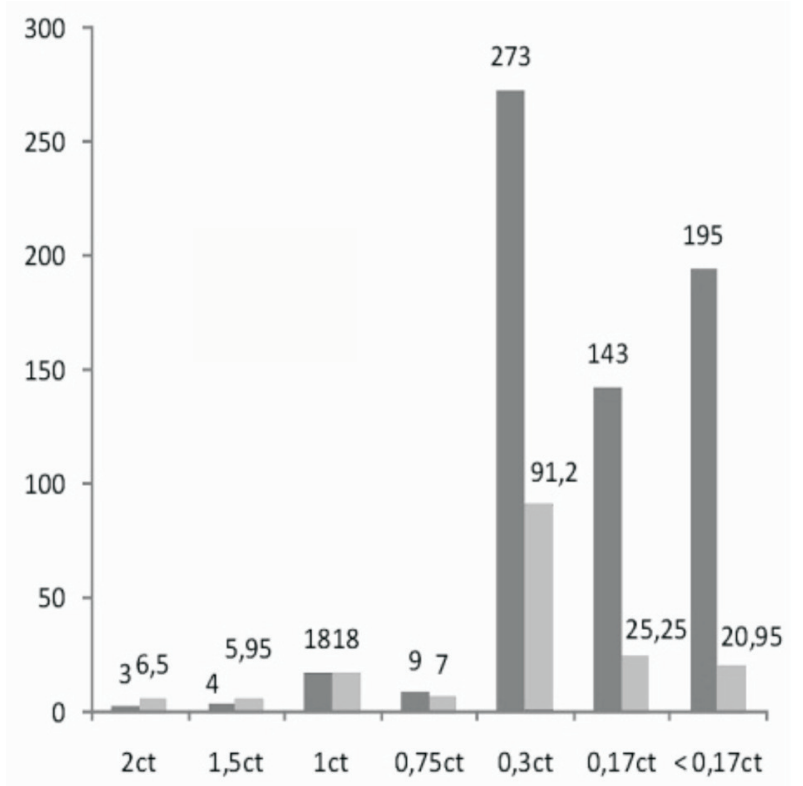

Figura 10 - Distribuição da quantidade de indivíduos (barras à esquerda) e peso dos diamantes (barras à direita) nos intervalos de tamanho entre menores que $0,17 \mathrm{ct}$ e maiores que $2 \mathrm{ct}$, numa população de 646 indivíduos classificados como "gema". Baseado nos dados de produção da Mineropar em 1985. Liccardo e Mesquita, 2010.

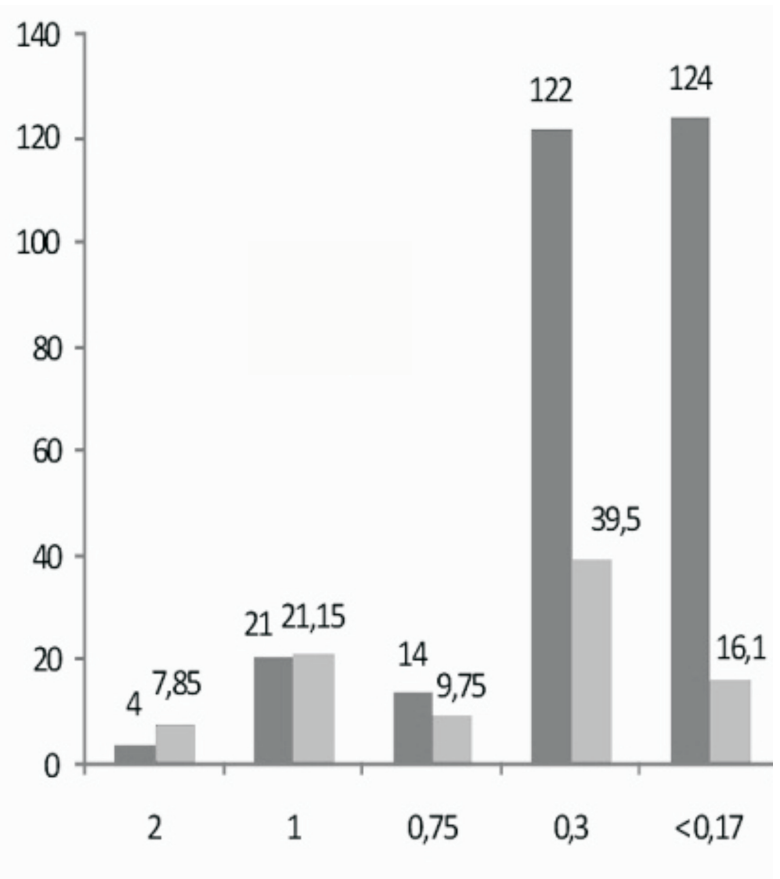

Figura 11 - Distribuição da quantidade de indivíduos (barras à esquerda) e peso dos diamantes (barras à direita) nos intervalos de tamanho entre menores que $0,17 \mathrm{ct}$ e maiores que $2 \mathrm{ct}$, numa população de 285 indivíduos classificados como "lasca". Baseado nos dados de produção da Mineropar em 1985. Liccardo e Mesquita, 2010.

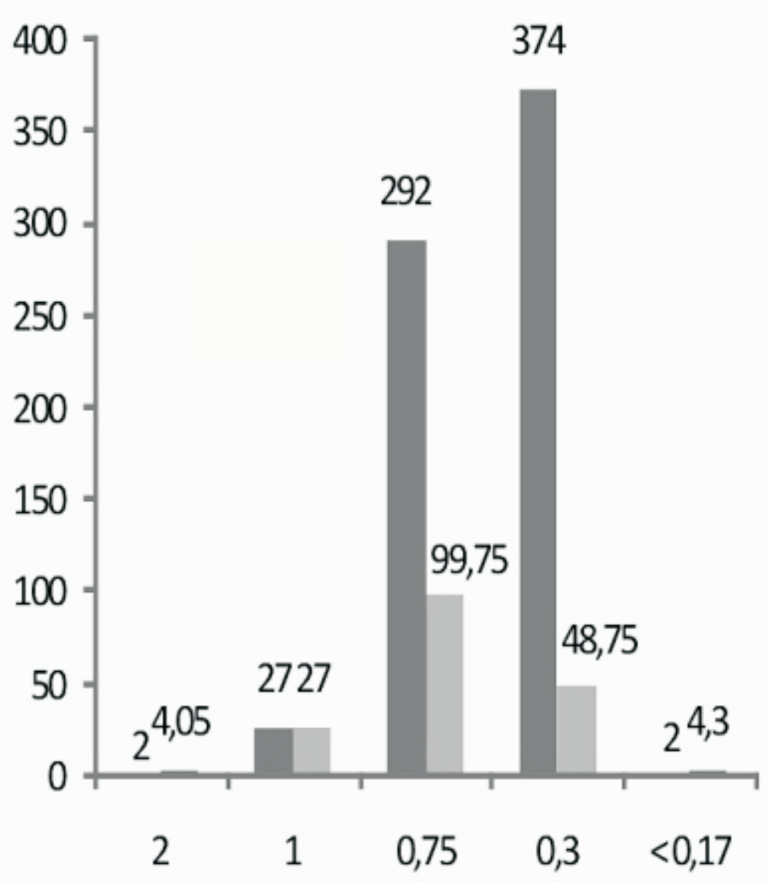

Figura 12 - Distribuição da quantidade de indivíduos (barras à esquerda) e peso dos diamantes (barras à direita) nos intervalos de tamanho entre menores que $0,17 \mathrm{ct}$ e maiores que $2 \mathrm{ct}$, numa população de 695 indivíduos classificados como "indústria". Baseado nos dados de produção da Mineropar em 1985. Liccardo e Mesquita, 2010. 


\subsection{SITUAÇÃO NO SÉCULO 21}

Mais recentemente, em 2005-2006, houve uma retomada na produção, com dezenas de dragas atuando ao longo do rio, entre Tibagi e Telêmaco Borba. Este fenômeno de aquecimento do mercado se explica parcialmente pela entrada do Brasil, nesta época, no sistema internacional de certificação de procedência de diamantes, conhecido como Processo Kimberley. Em 2006 a Mineropar editou um histórico da mineração no Paraná, onde os diamantes receberam papel destacado (Liccardo \& Cava, 2006). Irregularidades legais na mineração, problemas ambientais e a crise econômica internacional em 2009 levaram a um novo período de retração, situação que parece perdurar até o momento. Períodos de grande produtividade intercalados com períodos de grande recessão, somados ao desconhecimento da origem geológica ainda hoje parecem confirmar a história cíclica de extração de diamantes em Tibagi.

O maior rigor na fiscalização de impactos ambientais em leitos de rio, nos últimos anos, levou a grandes dificuldades na legalização de garimpos e na definição de áreas de extração. A recente construção de barragens para hidrelétricas sobre as áreas mais produtivas também gerou dificuldades para a extração, 0 que aponta para uma possível extinção desta atividade na região nos próximos anos.

Liccardo et al. (2012) propuseram uma abordagem como patrimônio cultural para todo o contexto do diamante em Tibagi e adjacências, discutindo a correlação entre as características dos garimpos, do diamante e sua gênese com a história local e o desenvolvimento peculiar que aconteceu nesta parte do Brasil. Em 2013, o governo estadual prepara uma legislação adequada para eventuais registros e tombamentos de patrimônios cultural e imaterial, onde possivelmente este conjunto de fatores possa vir a se enquadrar.

\section{DISCUSSÃO GEOLÓGICA}

Os garimpos de diamante da bacia hidrográfica do rio Tibagi (PR) e áreas adjacentes vêm sendo explorados desde o século dezoito, em cascalheiras do leito ativo dos rios, em aluviões antigos e recentes, bem como em colúvios. Estas ocorrências estão posicionadas sobre rochas da Formação Furnas (Devoniano) e do Subgrupo Itararé (Permo-Carbonífero), na porção sudeste da Bacia do Paraná e os depósitos são, em geral, de pequenas dimensões, tendo havido em alguns locais trabalhos mecanizados de lavra e de beneficiamento. 0 teor em diamante é baixo, oscilando entre 0,04 a 0,80 $\mathrm{ct} / \mathrm{m} 3$ nos níveis mais ricos. No decorrer dos anos oitenta, a produção dos garimpos oscilou entre 400 a $1.000 \mathrm{ct} /$ ano (Chieregati \& Svisero, 1990).

Svisero (1979) mostrou, por meio de análises em microssonda eletrônica, que inclusões de granada, espinélio e olivina contidas nestes diamantes, possuem características químicas típicas de diamantes peridotíticos, apontando uma derivação a partir de fontes essencialmente kimberlíticas. No decorrer de 1984, a CPRM e a Mineropar realizaram pesquisas de avaliação dos garimpos da região, ocasião em que foram classificados e avaliados os tipos de depósitos, tendo sido ressaltado o teor baixo das ocorrências (CPRM 1984,1986). A partir da década de 1980 houve uma intensa busca por kimberlitos no Brasil, como o Projeto Kimberlitos (Mineropar, 1986), mas a localização das fontes dispersoras destes diamantes do Paraná, contudo, ainda permanece desconhecida.

Chieregati et al. (1987) apresentaram um estudo prospectivo baseado no rastreamento de minerais pesados, a partir de uma amostragem regional realizada em garimpos dos rios Verde, Itararé, Jaguariaíva, Cinzas, Laranjinhas e Tibagi, cobrindo uma área de aproximadamente $200 \times 150 \mathrm{~km}$. Os resultados indicaram a presença de magnetita, ilmenita, cromita, jacobsita, limonita, granada, turmalina, epidoto, hornblenda, rutilo, monazita, xenotímio, apatita, zircão, estaurolita, cianita, anatásio, coríndon, cassiterita, sulfetos, ouro e diamante, com algumas variações de frequência nas áreas amostradas. Os minerais de interesse prospectivo, como a granada e a ilmenita, foram analisados com microssonda eletrônica e as análises químicas indicaram granada rica em $\mathrm{FeO}(25,55-34,68 \%)$, que corresponde ao termo almandina, derivada provavelmente de rochas do embasamento cristalino. Da mesma forma, os cristais de ilmenita são isentos de $\mathrm{MgO}$ e Cr2O3, impurezas típicas de ilmenitas kimberlíticas, tendo sido relacionadas também a rochas do embasamento (Chieregati \& Svisero, 1990).

A ausência dos indicadores tradicionais de kimberlitos (piropo cromífero, ilmenita magnesiana, cromita magnesiana e diopsídio cromífero), constituem uma situação geológica diferente daquela observada em outras regiões, como em Coromandel, Minas Gerais (Svisero et al., 2005), o que sugere que o diamante da região do Tibagi esteja relacionado a ciclos erosivos antigos. Outras evidências relativas ao diamante e à geologia da região reforçam essa possibilidade, como por exemplo:

a) diamantes de granulometria baixa e qualidade gemológica alta (\% de gemas entre 60 a 70\%), sugerindo transporte prolongado (Liccardo et al., 2010);

b) associação dos depósitos a unidades permocarboníferas da Bacia do Paraná, onde estão presentes litotipos derivados de glaciação (diamictitos);

c) presença de pavimentos estriados por ação de geleiras em rochas da região (Chieregati 1989, RochaCampos et al. 2008). 
As direções de paleocorrentes registradas nos litotipos (sedimentos do Grupo Itararé e rochas do embasamento) indicam transporte (pré ruptura do continente Gondwana) de S para N e NW (Santos et al., 1996). A associação desses fatos sugere que os diamantes da região do Tibagi foram transportados por processos glaciogênicos durante a deposição dos sedimentos permocarboníferos da Bacia do Paraná. As fontes dispersoras estariam situadas a sul dos depósitos atuais, possivelmente no continente africano em uma época anterior a fragmentação do Gondwana. Chieregati et al. (2010) apresentaram nova interpretação dos dados que confirmam a proveniência do diamante dos depósitos de origem glacial do Grupo Itararé. Não há evidências geoquímicas ou mineralógicas, ou mesmo datações dos diamantes até o momento, que pudessem corroborar algum destes modelos genéticos.

A história geológica destes diamantes apresenta pontos de especial fascínio e remetem a um amplo entendimento dos processos naturais que o planeta passou em termos temporais e espaciais. Esta história devidamente adaptada a outras linguagens pode ser utilizada como fator de cultura e educação científica, conforme os critérios preconizados pela UNESCO nas últimas décadas. Em termos de geologia regional, as características enigmáticas dos processos de deposição, desde a intemperização da rocha portadora (kimberlito) até as armadilhas de relevo fluvial, determinaram o tipo de mineração e a sua continuidade desde sua descoberta, há mais de 200 anos, até os dias de hoje, influenciando diretamente nos aspectos socioeconômicos locais.

\section{CARACTERÍSTICAS DOS DIAMANTES}

Conforme ressaltado por diversos autores, o diamante da região de Tibagi caracteriza-se pela predominância de pedras pequenas com peso médio variando entre 0,1 e 0,3ct. Chieregati (1989) estudou a distribuição do peso de diamantes de garimpos de Telêmaco Borba e de Tibagi a partir de um lote de 219 pedras, obtendo uma moda predominante em torno de 0,10 ct. Liccardo \& Mesquita (2010), descreveram um lote de 6.741 pedras com tamanho médio de 0,27ct, não obstante eventuais espécimes com até 10ct. Alguns relatos citam pedras de $107 \mathrm{ct}$, mas sem maior comprovação. Historicamente, não são conhecidas ocorrências de grandes diamantes na área de Tibagi, como aquelas registradas na região de Coromandel (MG), onde são frequentes pedras com dezenas ou mesmo centenas de quilates (Reis, 1959).

Chieregati (1989) caracterizou a morfologia a partir de vários lotes obtidos no leito ativo do rio Tibagi em 1985 , num total de 2.210 pedras. O exame individual dos exemplares permitiu identificar os principais hábitos cristalinos, estando presente por ordem de frequência decrescente: $61,0 \%$ de rombododecaedros, $16,0 \%$ de octarrombododecaedros, $10,3 \%$ de cristais irregulares, $5,7 \%$ de fragmentos de clivagem, $4,3 \%$ de octaedros, $1 \%$ de geminados, $1 \%$ de cristais cúbicos e $0,5 \%$ de agregados cristalinos. De modo geral, os diamantes são bem formados, euédricos, sendo pequeno o número de fragmentos de clivagem, como mostra a Figura 13.

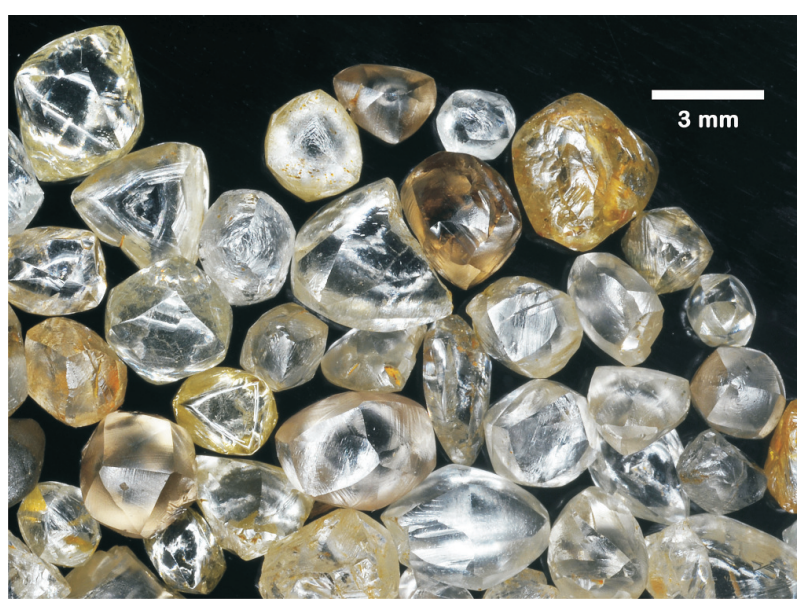

Figura 13 - Imagem parcial de um lote de 102 diamantes retirados de um colúvio (Lavra dos Ingleses, em Tibagi) em 2012. Os cristais enquadram-se perfeitamente em todas as descrições já realizadas desde o século XIX, mostrando considerável constância nas características físicas, como a predominância de formas de transição, como rombododecaedros ou hexatetraedros. Foto Liccardo, 2012.

O mesmo autor levantou as características de cor do diamante da região a partir de lotes de garimpos das regiões de Telêmaco Borba (130 pedras), Ortigueira (115 pedras), Rio Santa Rosa (21 pedras), e Campina dos Pupos (1.605 pedras), perfazendo um total de 2.115 exemplares. A análise do conjunto indicou a presença por ordem decrescente de 56,5\% de cristais incolores, $23,6 \%$ de castanhos claros, 9,7\% de castanhos escuros, $6,4 \%$ de amarelos e 3,6\% de verdes. Apesar dos diamantes apresentarem dimensões pequenas comparadas com outras áreas garimpeiras, eles se destacam pela presença de pedras coloridas (fancy colors), atualmente de grande valor no mercado.

Barelli (1973) identificou, por meio de difração de raios $X$, inclusões de olivina, enstatita e granada no interior de diamantes de garimpos do rio Tibagi. Meyer \& Svisero (1975) analisaram, por meio da microssonda eletrônica, cristais de piropo cromífero contendo até $17,5 \%$ de $\mathrm{Cr} 2 \mathrm{O} 3$ e de espinélio rico na molécula cromita. Svisero (1979) apresentou análises, também por microssonda, de olivina (forsterita), piroxênio (enstatita) e espinélio (cromita) e as características químicas destas inclusões indicam uma paragênese típica de diamantes peridotíticos.

Barelli (op.cit.) estudou um lote de 27 cristais por espectroscopia no infravermelho, onde constatou a predominância do tipo la, ou seja, diamantes contendo impurezas de nitrogênio. Liccardo et al. (2010) 
analisando um lote de 11 amostras de cores variadas, verificaram tratar-se de diamantes do tipo laAB. Este tipo de diamante é o mais comum na natureza e nele o nitrogênio ocorre na forma de agregados A, B e em grupos de três átomos conhecidos como N3. Estes centros absorvem parcialmente a luz causando colorações pálidas entre o amarelo e o castanho, e graus variados de fluorescência. Ainda segundo os referidos autores, os diamantes incolores apresentam os centros $A$ e B em proporções semelhantes. Nos diamantes castanhos predominam os centros $B$ e nos amarelos e verdes os centros $A$.

Uma das características marcantes dos diamantes da região de Tibagi é a predominância dos tipos gemológicos sobre os do tipo indústria, na proporção de 65/35\%, respectivamente. Outra qualidade gemológica de destaque é a presença de diamantes coloridos (fancy). Com relação à cor, a análise de um lote de 120 pedras baseada nos critérios do Gemological Institute of America (GIA), indicou a presença de $50 \%$ de diamantes incolores (categorias D a G), seguidos por 30 a $40 \%$ de cristais de cor castanha (categorias Q a R) e menos de $5 \%$ de diamante verde ou amarelo intenso (Liccardo et al., 2010). Embora não existam dados estatísticos em relação ao grau de pureza (clarity) dos diamantes de Tibagi, a prática comercial tem evidenciado a predominância de cristais com poucas inclusões e de bom aproveitamento na lapidação. Além disso, o predomínio de cristais euédricos em relação a fragmentos de clivagem (lascas) e agregados cristalinos é outro fator positivo no aproveitamento destes diamantes.

\section{INFLUÊNCIA SOCIOCULTURAL DA MINERAÇÃO}

Entre 1730 e 1733, o preço do diamante na Europa "despencou" pelo excesso de diamantes no mercado (Azevedo, 1988) e, a partir de 1740, a extração no Brasil passou a ser totalmente controlada pela Coroa Portuguesa, com direitos exclusivos para a compra dos diamantes produzidos. Esta situação perdurou até a independência em 1822 quando, então, volta a ser livre a procura por esta gema.

A mineração plena de diamante só veio a se desenvolver no Brasil com a chegada do século XIX, revelando grandes jazidas (Lins et al., 2000). Apesar de notícias sobre a existência de diamantes na Bahia (e no Paraná), a produção até então se concentrou em Minas Gerais. Segundo Martins et al. (1989), entre 1830 e 1865 houve a maior produção de diamantes no Brasil, superada logo depois pela descoberta dos riquíssimos depósitos na África. A maior parte dos autores atribui a decadência na mineração à perda de valor econômico no mercado internacional em função das pedras que chegavam das minas africanas.

Apesar do papel periférico da mineração em Tibagi, o conhecimento da população sobre a existência do diamante remonta ao século XVIII, o que diferencia culturalmente esta região de qualquer outra do Paraná e até mesmo do sul do Brasil. A articulação entre exploração mineral e as práticas culturais costuma se refletir nas características singulares dos lugares de ocorrência, neste caso o município de Tibagi, principalmente, e outros nos arredores, como Telêmaco Borba, Ortigueira ou Jaguariaíva.

A cultura de mineração esteve desde o início arraigada aos primeiros desbravadores (brancos) do território e teve grande impulso no século $X X$, com a vinda dos mineradores de Minas Gerais e Bahia, negros e mulatos em sua maioria. A miscigenação da população, desde então, causou um enriquecimento cultural que se reflete hoje no folclore, músicas e no imaginário dos habitantes da região. Tibagi tem hoje uma das maiores populações negras do Paraná. Boa parte da história econômica de Tibagi também está relacionada aos aquecimentos (e rupturas) da economia da mineração, assim como às flutuações populacionais com levas de mineradores que iam e vinham conforme as épocas de maior ou menor produção (Liccardo et al., 2012).

Diversamente de outras áreas diamantíferas no Brasil, onde grandes achados fizeram fortunas imediatas e trouxeram, como consequência, o aumento de violência e o extremo contraste social, em Tibagi há uma tendência para a produção de pedras pequenas, o que possivelmente causou um impacto menor e determinou a extração paulatina, sem grandes surtos. Não obstante, a participação desta extração mineral na economia local apresentou inúmeros reflexos, entre eles o assentamento de boa parte dos garimpeiros que vieram a compor a população da região.

O Museu Histórico Desembargador Edmundo Mercer, também chamado Museu do Garimpo, é conhecido como um dos mais importantes acervos do Paraná. Criado em 1985 com a proposta de manutenção cultural da história do município, destacou-se pelo conteúdo ligado ao garimpo, sendo sua principal sala de exposições o único local da região Sul do Brasil a apresentar os objetos, imagens e textos sobre o tema da mineração. Dos museus diretamente ligados à história do diamante no Brasil, o museu de Tibagi figura entre os mais completos e bem documentados, além de constituir atualmente um atrativo turístico obrigatório do município. Uma das salas do museu também é dedicada à participação dos negros na formação da identidade cultural do município (Liccardo et al., 2012).

\section{CONTEXTO DO DIAMANTE COMO PATRIMÔNIO IMATERIAL}

A Constituição Federal de 1988, em seus artigos 215 e 216, ampliou a noção de patrimônio cultural ao reconhecer a existência de bens culturais de natureza material e imaterial e, também, ao estabelecer outras formas de preservação - como o Registro e o Inventário - 
além do Tombamento, instituído pelo Decreto-Lei no. 25, de 30/11/1937, que é adequado, principalmente, à proteção de edificações, paisagens e conjuntos históricos urbanos (IPHAN, 2013). Os Bens Culturais de Natureza Imaterial dizem respeito àquelas práticas e domínios da vida social que se manifestam em saberes, ofícios e modos de fazer; celebrações; formas de expressão cênicas, plásticas, musicais ou lúdicas; e nos lugares, como mercados, feiras e santuários que abrigam práticas culturais coletivas.

A Organização das Nações Unidas para a Educação, a Ciência e a Cultura (UNESCO) define como Patrimônio Cultural Imaterial:

\begin{abstract}
"as práticas, representações, expressões, conhecimentos e técnicas - com os instrumentos, objetos, artefatos e lugares culturais que Ihes são associados - que as comunidades, os grupos e, em alguns casos os indivíduos, reconhecem como parte integrante de seu patrimônio cultural".
\end{abstract}

Esta definição está de acordo com a Convenção da UNESCO para a Salvaguarda do Patrimônio Cultural Imaterial, ratificada pelo Brasil em março de 2006 (IPHAN, 2013). Como patrimônio cultural ou imaterial estão compreendidas, então, as possibilidades de utilização dos recursos naturais para os mais variados fins, bem como as práticas cotidianas relacionadas ao modo de vida, organizado no que se pode chamar de experiências vividas. O patrimônio cultural, representado tanto pela cultura erudita quanto pela cultura popular, pode ser identificado nas manifestações sociais atuais, e mais do que isso, pode ser considerado elemento importante na formação sociocultural das populações que lhe são recorrentes.

Desde a década de 1970, a relação da sociedade com as práticas cotidianas passou a receber atenção e valorização, sendo considerada como patrimônio imaterial, uma memória que contribui com o entendimento da ordenação social, espacial e econômica, como, aliás, pode ser encontrado nos municípios do Paraná ligados à extração de diamante. 0 patrimônio cultural torna-se incorporado à sociedade quando, associada a ele, a memória social é fixada através de elementos que possuem significado para a vida coletiva, e a importância deste patrimônio está diretamente relacionada à carga simbólica que ele representa, assim como ao poder de pertencimento que ele proporciona (Monastirsky, 2005). A história do diamante em Tibagi refere-se a esta carga de simbolismo e certamente exerce papel fundamental na cultura local.
Tibagi e Telêmaco Borba, os principais municípios produtores de diamante, apresentaram uma evolução socioeconômica diferente da maioria dos municípios da região, como Castro, por exemplo, cuja influência da pecuária e do tropeirismo no século XIX impregnou culturalmente de maneira diversa do que a prática garimpeira. Mesmo o número de escravos ligadosà mineração foi muito inferior aos utilizados nas fazendas ligadas à pecuária e, mais ainda, sem comparação com áreas mineradoras de Minas Gerais ou Bahia. Certamente a extração de diamante no sul do país não recebeu a mesma ênfase de outras áreas e por isso seus ciclos de altos e baixos não tiveram impacto negativo tão profundo. Esta característica, por si só, faz desta história de extração algo diferente de outros lugares do Brasil e permitiu a longevidade desta atividade de maneira artesanal.

As grandes cheias do rio Tibagi tornam inviáveis os trabalhos em certas épocas do ano, obrigando à sazonalidade na atividade extrativa e impondo atividades paralelas de subsistência aos garimpeiros (como a agricultura, por exemplo). Diamantes grandes são extremamente raros e, na maior parte dos casos, o tamanho pequeno das pedras limita os ganhos, não obstante serem de ótima qualidade gemológica. O desconhecimento de sua origem geológica ou, mais especificamente, de sua rocha-fonte dificulta projetos racionais que proponham um planejamento nos moldes de uma mineração moderna. Esta conjuntura faz com que a atividade de mineração seja de pequeno porte e com tendência a utilizar técnicas tradicionais de trabalho artesanal. Possivelmente os aspectos histórico-culturais deste processo representem maior valor para a comunidade que o aspecto econômico ligado a esta atividade, no caso desta região.

Com a construção de barragens para hidrelétricas no rio Tibagi é possível que a garimpagem, nos moldes em que é praticada atualmente, seja extinta. A proposta desta discussão é que se busquem mecanismos de preservação e valorização do conteúdo histórico-cultural e sejam avaliados seus impactos sobre a sociedade e a memória local. O conhecimento e as reflexões geológicas devem ser considerados um importante instrumento para alicerçar este processo, por apresentar dados consistentes e registros de alta confiabilidade. Assim como estes dados costumam balizar pesquisas de prospecção geológica, podem ser utilizados também para balizar o registro como patrimônio imaterial do Paraná. 


\section{Referencias}

ANDRADA M. F. R. 1847. Diário de uma Viagem Mineralógica pela Província de S. Paulo no Anno de 1805. Revista do IHGSP, Tomo IX, pp. 527-548.

AZEVEDO J. L. 1988. Épocas de Portugal Económico Clássica Editora, Lisboa.

BARELLI N. 1973. Contribuição ao estudo do diamante do rio Tibagi, Paraná. Tese de Doutoramento, Departamento de Química, FFCL, Araraquara, 124p.

BASTOS A.A. 1936. Exploração do rio Tibagi. In: Brasil, Serviço Geológico e Mineralógico, Rel. Anual da Diretoria, Rio de Janeiro, 148 pp, 53-62.

BIGG-WITHER, T.P. 1878. Novo Caminho no Brasil Meridional: a Província do Paraná (três anos em suas florestas e campos) - 1872-1875. Rio de Janeiro, J. Olympio, 1974, $420 \mathrm{pp}$.

CHIEREGATI L.A. 1989. Aspectos mineralógicos, genéticos e econômicos das ocorrências diamantíferas da região nordeste do Paraná e sul de São Paulo. Dissertação de Mestrado, Instituto de Geociências, USP, 180p.

CHIEREGATI L.A.; OLIVEIRA J.P.; SVISERO D.P. 1987. Estudo prospectivo das ocorrências diamantíferas do Rio Verde, estado de São Paulo. Atas do 6ㅇ. Simpósio Regional de Geologia, Rio Claro, v. 2, p. 471-480.

CHIEREGATI L.A. \& SVISERO D.P. 1990. Estudo de minerais pesados na região diamantífera do rio Tibagi (PR) e as possibilidades de existência de fontes primárias na região. Acta Geológica Leopoldensia, 30:171-186.

CHIEREGATI L.A.; SVISERO, D.P.; LICCARDO A. 2010. Aspectos mineralógicos e genéticos do diamante da região de Tibagi, Paraná. In 5오 Simpósio Brasileiro de Geologia do Diamante. Anais, Curitiba, p. 54-55.

CPRM. 1984. Projeto mapas metalogenéticos e de previsão de recursos minerais. Folha SG.22-X-A, Telêmaco Borba, DNPM/CPRM, vols. 1 e 2.

CPRM. 1986. Projeto borda leste da Bacia do Paraná: integração geológica e avaliação econômica. Relatório final, vols. 1, 2 e 3.

DERBY O A .1878. A Geologia da Região Diamantífera da Província do Paraná. Archivos do Museu. Nacional., 3:89-98, Rio de Janeiro.

ESCHWEGE W.L. 1833. Pluto Brasiliensis. São Paulo/Belo Horizonte, Edusp/Itatiaia, 1979, vol 2, 210 pp.

GUIMARÃES D. 1933. A Província Magmática do Brasil Meridional. Monografia I do Serviço Geológico de Minas Gerais.

GUTIERREZ H. 2006. Donos de terras e escravos no Paraná: padrões e hierarquias nas primeiras décadas do século XIX. História. São Paulo, v.25, n.1 p.100122.

HARTT C.F. 1870. Geology and Physical Geography of Brazil. R. Krieger, Huntington, 620 pp, 1975.

IPHAN. 2013. Instituto do Patrimônio Histórico e Artístico Nacional. Patrimônio Imaterial. http://portal.iphan.gov.br
LICCARDO A. \& CAVA L.T. 2006. Minas do Paraná. Imprensa Oficial. Curitiba: Sesquicentenário, 2006. $165 \mathrm{pp}$.

LICCARDO A.; SVISERO D.P.; DEREPPE J.M. 2010. Características mineralógicas do diamante da região do Tibagi, Paraná. In 5o Simpósio Brasileiro de Geologia do Diamante. Anais, Curitiba, p. 27-29.

LICCARDO A.; MESQUITA D. 2010. Extração de diamante no rio Tibagi (PR) em lavra experimental nos anos 1980. In 5o Simpósio Brasileiro de Geologia do Diamante. Anais, Curitiba, p. 27-29.

LICCARDO A.; BARBOSA T.A.; HORNES K.L. 2012. Diamante de Tibagi no Paraná - Patrimônio Geológico-Mineiro e Cultural. Anuário do Instituo de Geociências-UFRJ. V. 35. P.142-151.

LINS, F.; LOUREIRO F.; ALBUQUERQUE G. 2000. Brasil 500 anos - a construção do Brasil e da América Latina pela Mineração. Rio de Janeiro, CETEM. 254pp.

LOPES J.C.V. 2002. Introdução à História de Tibagi. Acad. Paranaense de Letras, 198p.

MAACK R. 1968. Diamante no tilito de Tibagi, Paraná. Anais da Academia Brasileira de ciências, v 40, p.96, 1968. (suplemento).

MARTINS R.B.; BRITO O.E.A.; FALZONI R. 1989. História da mineração no Brasil - Empresa das Artes, São Paulo.

MERCER E. A. \& MERCER L. L. 1934. História de Tibagi. Gráfica Linarth, Curitiba. 196 pp.

MEYER H.O.A. \& SVISERO D.P. 1975. Mineral inclusions in brazilian diamonds. Physics and Chemistry of Earth, 9: 785-795.

MINEROPAR. 1986. Projeto Kimberlitos. Vol 1. 125p.

MONASTIRSKY L.B. 2005. Espaço Urbano: Memória Social e Patrimônio Cultural, Revista Terra Plural, Ponta Grossa, PR.

OLIVEIRA E.P. 1927. Geologia e Recursos Minerais do estado do Paraná. Monografia - SGM, Rio de janeiro, n. 6.

OLIVEIRA A. P. 1937. Contribuição à geologia do município de Tibagy. In: Brasil, Serviço Geológico e Mineralógico, Rel. Anual da Diretoria, Rio de Janeiro, $148 \mathrm{pp}, 62-71$.

OPPENHEIM V. 1936. Sedimentos diamantíferos do Paraná. DNPM/SFPM, Rio de Janeiro, avulso n. 9, 14 pp.

PERDONCINI L.C. 1997. Diamantes do rio Tibagi: fonte no grupo Itararé? Dissertação de Mestrado. DEGEOLUFPR, $138 \mathrm{p}$.

REIS E. 1959. Os grandes diamantes brasileiros. Boletim DNPM/DGM no191, 65p.

ROCHA-CAMPOS A.C.; SANTOS P.R.; CANUTO J.R. 2008. Late paleozoic glacial deposits of Brazil: Paraná Basin. The Geological Society of America, Special Paper 441, 97-114. 
SAINT-HILAIRE A. 1820. Viagem a Curitiba e Província de Santa Catarina. Ed. Itatiaia, São Paulo, 1978. 209 pp.

SANTOS P.R.; ROCHA-CAMPOS A.C.; CANUTO J.R. 1996. Patterns of late Palaeozoic deglaciation in the Paraná Basin, Brazil. Palaeogeography, Palaeoclimatology, Palaeoecology, 125: 165-184.

SVISERO D.P. 1979. Inclusões minerais e gênese do diamante do rio Tibagi, Paraná. Atas do 2‥ Simpósio Regional de Geologia, Rio Claro, v. 2, p.169-180.

SVISERO D.P.; ULBRICH M.N.C.; VLACH M.A.S.; BASEI R.A.; SCHULTZ-GLÜTTER R.A. 2005. Geologia e petrologia de minerais resistatos das intrusões Vargem, Coromandel, Minas Gerais. In: SIMPÓSIO BRASILEIRO DE GEOLOGIA DO DIAMANTE, 4, Diamantina. Anais... Diamantina: SBG-MG, p.173-176. 